\title{
Human aldose reductase expression accelerates diabetic atherosclerosis in transgenic mice
}

\author{
Reeba K. Vikramadithyan, ${ }^{1}$ Yunying Hu, ${ }^{1}$ Hye-Lim Noh, ${ }^{1}$ Chien-Ping Liang, ${ }^{2}$ Kellie Hallam, ${ }^{3}$ \\ Alan R. Tall, ${ }^{2}$ Ravichandran Ramasamy, ${ }^{3}$ and Ira J. Goldberg ${ }^{1}$ \\ 1Department of Medicine, Division of Preventive Medicine and Nutrition and Division of Cardiology, ${ }^{2}$ Department of Medicine, Division of Molecular Medicine, \\ and ${ }^{3}$ Department of Surgery, Columbia University, New York, New York, USA.
}

\begin{abstract}
Direct evidence that hyperglycemia, rather than concomitant increases in known risk factors, induces atherosclerosis is lacking. Most diabetic mice do not exhibit a higher degree of atherosclerosis unless the development of diabetes is associated with more severe hyperlipidemia. We hypothesized that normal mice were deficient in a gene that accelerated atherosclerosis with diabetes. The gene encoding aldose reductase (AR), an enzyme that mediates the generation of toxic products from glucose, is expressed at low levels in murine compared with human tissues. Mice in which diabetes was induced through streptozotocin (STZ) treatment, but not nondiabetic mice, expressing human AR (hAR) crossed with LDL receptor-deficient ( $\mathrm{Ldlr}^{-/-}$) C57BL/6 male mice had increased aortic atherosclerosis. Diabetic hAR-expressing heterozygous LDL receptor-knockout mice $\left(\mathrm{Ldll}^{+/-}\right)$ fed a cholesterol/cholic acid-containing diet also had increased aortic lesion size. Lesion area at the aortic root was increased by STZ treatment alone but was further increased by hAR expression. Macrophages from hARtransgenic mice expressed more scavenger receptors and had greater accumulation of modified lipoproteins than macrophages from nontransgenic mice. Expression of genes that regulate regeneration of glutathione was reduced in the hAR-expressing aortas. Thus, hAR increases atherosclerosis in diabetic mice. Inhibitors of AR or other enzymes that mediate glucose toxicity could be useful in the treatment of diabetic atherosclerosis.
\end{abstract}

\section{Introduction}

Although people with both type 1 and type 2 diabetes develop increased atherosclerosis, which leads to more heart attacks and strokes, direct evidence that this is mediated by hyperglycemia is lacking. In part, this is because additional atherogenic factors such as lipid abnormalities and hypertension accompany the diabetes $(1,2)$. Efforts to demonstrate the presumed toxic effects of hyperglycemia in experimental animals have been similarly hindered (3). Diabetes has been superimposed onto wild-type and atherosclerosis-prone mice in an attempt to reproduce the relationship between diabetes and macrovascular disease. However, a clear model of diabetes-induced accelerated atherosclerosis is lacking. In several situations, genetic insulin resistance and streptozotocin-mediated (STZ-mediated) destruction of islet cells produced greater hyperlipidemia and, not surprisingly, more atherosclerosis (4). This was noted in both LDL receptorknockout $\left(\operatorname{Ldlr}^{-/-}\right)(5,6)$ and apoE-knockout mice $(7)$. In a recent study, chow-fed $L d l r^{-/-}$diabetic mice had more atherosclerosis at the aortic root, but when these mice were fed cholesterol-containing diet, the atherosclerosis correlated with plasma cholesterol and not glucose (8). Thus, as in many previous reports, the more advanced vascular lesions in these mice were attributable to greater hyperlipidemia and not hyperglycemia or defective insulin actions.

Nonstandard abbreviations used: Ac-LDL, acetyl-LDL; AR, aldose reductase; CCA, cholesterol/cholic acid-containing; G6PD, glucose 6 phosphate dehydrogenase; GSH-px, glutathione peroxidase; hAR, human AR; HCD, high-cholesterol diet; mAR, mouse AR; SR-A, scavenger receptor-A; STZ, streptozotocin.

Conflict of interest: The authors have declared that no conflict of interest exists.

Citation for this article: J. Clin. Invest. 115:2434-2443 (2005).

doi:10.1172/JCI24819.
In other models, diabetes failed to accelerate vascular pathology. This was the case in studies of STZ-induced diabetes in $\mathrm{Ldlr}^{-/-}(9)$ and human apoB-overexpressing mice (10) and in a high-fat diet model of insulin resistance, mild diabetes, and obesity (11). In these cases, the diabetes did not significantly alter plasma lipid levels. Thus, the mouse appears to have limited ability to develop pathological changes attributable to diabetes alone. One explanation for this might be that mice are genetically deficient in an enzyme required for the toxic actions of hyperglycemia. The lack of animals that develop diabetic macrovascular disease has led to the establishment of an NIH-sponsored program to produce such models, the Animal Models of Diabetic Complications Consortium (AMDCC; www.amdcc.org).

The results in mouse models of diabetes and atherosclerosis appear to conflict with the many illustrations of generation of ROS and inflammatory processes in cultured cells exposed to high glucose levels (12). Aldose reductase (AR) catalyzes the reduction of glucose, an aldehyde-containing sugar, to sorbitol. AR mediates 1 of several pathways thought to accelerate diabetic complications via production of excess ROS. Although previous clinical trials using AR inhibitors to prevent or treat diabetic complications have been disappointing $(13,14)$, more recent studies suggest that $\mathrm{AR}$ inhibition is beneficial for diabetic neuropathy $(15,16)$. AR has been implicated as a cause of increased cardiac ischemic injury in rats (17), and AR inhibitor therapy was associated with improvement of human cardiac function (18). Transgenic AR expression amplifies the pathological response to ischemia/reperfusion in mice (19). Studies comparing protein levels have shown that mice normally have much lower levels of AR (19) than humans $(20,21)$.

We postulated that greater expression of a gene involved in the toxic metabolism of glucose would accelerate hyperglycemia- 

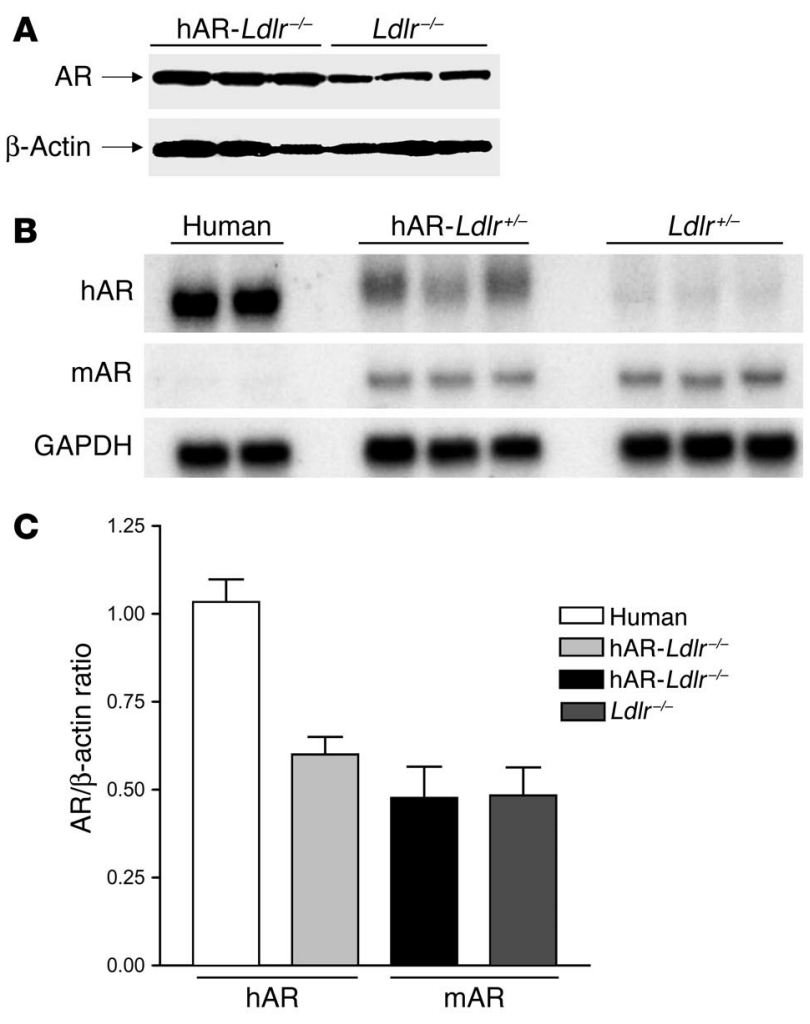

induced macrovascular disease. To test this, we crossed mice expressing human AR (hAR) (22) with atherosclerosis-prone $L d l r^{-/-}$mice and assessed the effects of diabetes on atherosclerosis development. Our data show that AR expression modulates atherosclerosis development in diabetic animals and confirm that hyperglycemia alone, in the proper genetic background, accelerates atherosclerosis.

\section{Figure 1}

Expression of $A R$ in transgenic mice, normal human hearts, and macrophages. (A) Western blot of AR protein in aortas from $\mathrm{Ldll}^{-1-}$ and hARLdll $r^{-/}$mice. Aortas were obtained from 8-week-old mice on chow diets, the aortas were harvested and homogenized, and equal amounts of protein were loaded on SDS gels. AR was detected using a polyclonal antibody that recognizes both human and mAR. (B) Northern blot analysis of heart expression of human and mAR gene. (C) Real-time PCR analysis of macrophage expression of hAR and mAR mRNA. Values are expressed as mean $\pm \mathrm{SEM} ; n=5$ mice per group. For human macrophages, 2 samples were assayed in duplicate 3 times.

expression in macrophages from transgenic mice, assessed by realtime PCR and normalized to $\beta$-actin, was not greater than that in human cells. Therefore, presence of the hAR transgene increased total AR expression but did not lead to levels of AR that greatly exceeded those in the human cells.

Diabetes increased plasma cholesterol levels regardless of AR expression. To determine whether this level of AR expression was sufficient to alter vascular responses to hyperglycemia, we analyzed lesion development in control and STZ-treated diabetic $L d l r^{-/-}$mice with or without hAR expression. STZ treatment of male mice led to a 3-fold increase in glucose after 6 weeks of a high-cholesterol diet (HCD). The glucose elevation persisted in mice followed for 12 weeks; the mice were given free access to water but were not treated with insulin. As we had reported previously, diabetes in these mice was associated with an inhibition of growth; both the hAR- and non-hARexpressing mice failed to gain weight, as did the nondiabetic mice $(10,24)$. Creatinine levels were not significantly increased by either diabetes or hAR expression: $\mathrm{Ldlr}^{-/-}, 0.19 \pm 0.26 \mathrm{mg} / \mathrm{dl}$; STZ-treated $L d l r^{-/-}, 0.28 \pm 0.18 \mathrm{mg} / \mathrm{dl}$; hAR- $L d l^{-/-}, 0.18 \pm 0.27 \mathrm{mg} / \mathrm{dl}$; and STZ-treated hAR-Ldlr ${ }^{-/}, 0.15 \pm 0.17 \mathrm{mg} / \mathrm{dl}$. hAR expression also did not alter liver functions.

Diabetes markedly increased plasma cholesterol levels, regardless of the expression of AR (Table 1). Diabetic mice had cholester-

\section{Results}

hAR-expressing mice have lower AR expression than normal buman hearts and macrophages. The extent of alteration in AR expression by the hAR transgene was first assessed. Aortic tissues from $\mathrm{Ldlr}^{-/-}$mice with (hAR-Ldlr $r^{-/-}$) and without hAR transgene expression were used for Western blotting and measurements of AR activity (23). As shown in Figure 1A, hAR led to a 3- to 4-fold increase in AR protein expression. A similar increase in AR activity was found: $L d l r^{-/-}$had $1.19 \pm 0.38 \mu \mathrm{mol}$ and hAR-Ldlr-/- had $4.15 \pm 0.89 \mu \mathrm{mol}$ of NADPH/ min. To determine whether human and mouse tissues express similar levels of AR, we obtained mRNA from human as well as wild-type (C57BL/6) and hAR-transgenic mouse tissues. Mouse AR (mAR) mRNA levels in hearts (Figure 1B) and macrophages (Figure 1C) were not altered by hAR expression. AR mRNA levels compared with levels in human hearts (normalized to a common GAPDH) were greater than the endogenous mAR. Transgenically expressed hAR mRNA was still lower than that in normal human hearts. Consistent with data on mouse (19) and human (21) AR protein levels, hAR transgene expression increased but did not fully compensate for mAR deficiency. Similarly, hAR

\section{Table 1}

Blood glucose and lipid profile in control and STZ-treated male mice fed an HCD for 6,8 , and 12 weeks

\begin{tabular}{|c|c|c|c|c|}
\hline & $\begin{array}{c}L d I r^{-/} \\
(n=14)\end{array}$ & $\begin{array}{c}\text { hAR-LdIr-l- } \\
\quad(n=13)\end{array}$ & $\begin{array}{l}\text { LdIr-l- STZ } \\
\quad(n=11)\end{array}$ & $\begin{array}{c}\text { hAR-LdIr-l-STZ } \\
\quad(n=16)\end{array}$ \\
\hline \multicolumn{5}{|l|}{6 weeks } \\
\hline Glucose (mg/dl) & $147 \pm 6$ & $148 \pm 8$ & $530 \pm 32^{A}$ & $473 \pm 22^{A}$ \\
\hline $\mathrm{TC}(\mathrm{mg} / \mathrm{dl})$ & $1,569 \pm 2$ & $1,358 \pm 158$ & $3,033 \pm 275^{A}$ & $3,302 \pm 269 \mathrm{~A}$ \\
\hline TG (mg/dl) & $90 \pm 4$ & $93 \pm 9$ & $130 \pm 10$ & $149 \pm 16$ \\
\hline $\mathrm{HDL}(\mathrm{mg} / \mathrm{dl})$ & $58 \pm 3.7$ & $51 \pm 4.5$ & $58 \pm 9.1$ & $67 \pm 5.2$ \\
\hline \multicolumn{5}{|l|}{8 weeks $(n=5)$} \\
\hline Glucose (mg/dl) & $151 \pm 10$ & $143 \pm 8$ & $461 \pm 49 A$ & $461 \pm 66^{A}$ \\
\hline $\mathrm{TC}(\mathrm{mg} / \mathrm{dl})$ & $711 \pm 63$ & $898 \pm 92$ & $2,566 \pm 451^{A}$ & $2,568 \pm 409^{A}$ \\
\hline TG (mg/dl) & $104 \pm 9$ & $123 \pm 30$ & $175 \pm 49$ & $213 \pm 61$ \\
\hline $\mathrm{HDL}(\mathrm{mg} / \mathrm{dl})$ & $69 \pm 5$ & $66 \pm 8$ & $56 \pm 8$ & $70 \pm 3$ \\
\hline \multicolumn{5}{|l|}{12 weeks $(n=5)$} \\
\hline Glucose (mg/dl) & $114 \pm 7$ & $115 \pm 13$ & $493 \pm 63^{A}$ & $472 \pm 83^{A}$ \\
\hline $\mathrm{TC}(\mathrm{mg} / \mathrm{dl})$ & $1,178 \pm 127$ & $1,116 \pm 225$ & $3,528 \pm 87^{A}$ & $3,667 \pm 58^{A}$ \\
\hline TG (mg/dl) & $77 \pm 8$ & $121 \pm 25$ & $117 \pm 21$ & $88 \pm 8$ \\
\hline $\mathrm{HDL}(\mathrm{mg} / \mathrm{dl})$ & $69 \pm 5$ & $65 \pm 8$ & $59 \pm 4$ & $64 \pm 6$ \\
\hline
\end{tabular}

Data are expressed as mean \pm SEM. ${ }^{A} P<0.05$ relative to nondiabetic controls. Lipid measurements were performed in plasma samples from 6-hour fasted mice. Glucose was measured in whole blood using a glucometer. TC, total cholesterol; TG, triglyceride. 
A

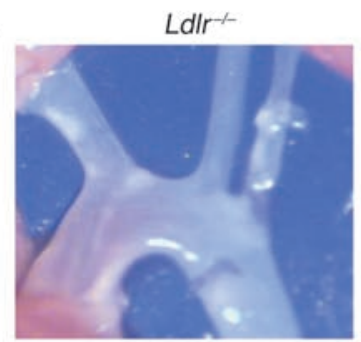

B

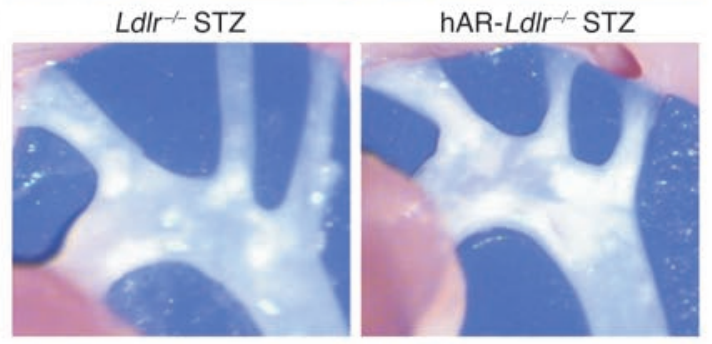

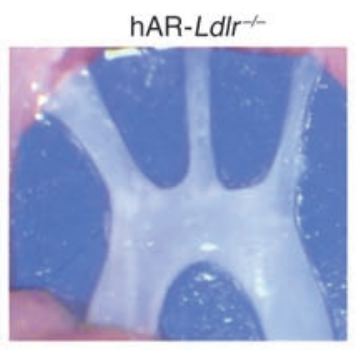

Figure 2

C

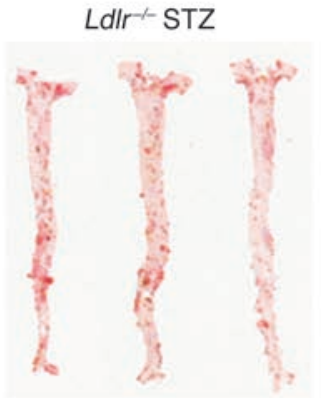

D

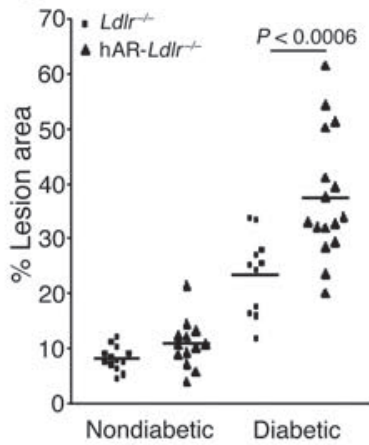

hAR-Ldlr $r^{-1-}$ STZ

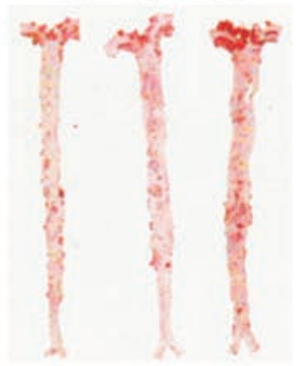

E

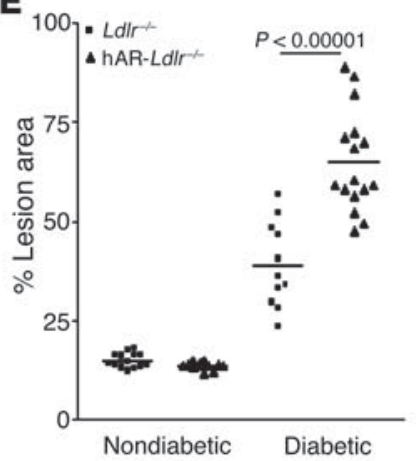

Diabetes increased the atherosclerosis lesion size in male hAR-Ldlr--- mice fed the HCD for 6 weeks. (A) Aortic arch lesion area in $L d l r^{-1-}$ and hAR$L d l r^{--}$nondiabetic mice. (B) Aortic arch lesion area in Ldlr $r^{--}$and hAR-Ldlr $r^{--}$diabetic mice. Magnification, $\times 26$. (C) Oil red O staining of en face lesion area of $L d l r^{-1-}$ and hAR-Ldlr $r^{-1-}$ diabetic mice. (D) Total lesion area in nondiabetic and diabetic $L d l r^{-1-}$ and hAR-Ldlr $r^{-1-}$ mice. (E) Aortic arch lesion area in nondiabetic and diabetic Ldlr-/- and hAR-Ldl/r-/- mice.

ol levels that were approximately twice those of nondiabetic mice after 6 weeks and approximately 3 times those of nondiabetic mice after 8 and 12 weeks of HCD feeding. Average triglyceride levels were higher after 6 and 8 weeks, but not 12 weeks, in diabetic mice. HDL cholesterol was not significantly altered between the $\mathrm{Ldlr}^{-/-}$ and hAR- $L d l r^{-/}$mice or between the control and STZ groups. In summary, STZ treatment led to sustained diabetes and a marked increase in non-HDL cholesterol levels. hAR expression did not alter the diabetogenic effect of STZ or the plasma lipids.

Diabetes increased atherosclerosis lesion size in mice expressing $h A R$. Atherosclerosis was assessed in mice fed the HCD after 6 weeks (Figure 2). The percent of the aorta covered with atherosclerotic lesions was much lower in nondiabetic mice (Figure 2A), as would be expected based on their lower cholesterol levels, and was not altered by hAR expression. Consistent with the hypothesis that $\mathrm{AR}$ repletion is required in order for hyperglycemia to have toxic effects, hAR expression led to a marked increase in lesion size in STZ-treated mice (Figure 2, B and C). hAR expression increased the percent of the total lesion area in the diabetic mice from $23.4 \% \pm 2.2 \%$ in $L d l r^{-/-}$to $37.5 \% \pm 2.7 \%$ in hAR- $\mathrm{Ldlr}^{-/-}$mice; the total lesion area in nondiabetic mice averaged $8.0 \% \pm 0.6 \%$ in $\mathrm{Ldlr}^{-/-}$and $10.7 \% \pm 1.2 \%$ in hAR-Ldlr ${ }^{-/}$mice (Figure $2 \mathrm{D}$ ). The most marked increase in lesion area was in the aortic arch, where the hAR led to a greater than $65 \%$ increase: $39.1 \% \pm 3.2 \%$ in $\mathrm{Ldlr}^{-/}$to $65.0 \% \pm 3.0 \%$ in hAR-Ldlr ${ }^{-/}$mice; the lesion area in nondiabetic mice averaged $14.9 \% \pm 0.5 \%$ in $\mathrm{Ldll}^{-/-}$to $13.7 \% \pm 0.3 \%$ in hAR- $L d l r^{-/}$mice (Figure $2 \mathrm{E}$ ). These findings indicate that hAR expression markedly increases atherosclerosis, but only in diabetic mice. The disease was independent of changes in plasma lipid levels. Because on the HCD, diabetes markedly increased plasma cholesterol, as was noted in other models $(5,8)$, the smaller lesions in nondiabetic animals probably reflected their relatively lower circulating lipid levels. Overall, the data suggest that hAR mediates toxic effects on the blood vessel only in the presence of hyperglycemia.

Atherosclerosis lesion size increased with longer high-cholesterol feeding. Nondiabetic and diabetic $L d l r^{-/-}$and hAR-Ldlr $r^{-/}$mice fed an HCD were sacrificed after 8 and 12 weeks of feeding. A similar hARinduced increase in lesion size was found in diabetic mice fed the HCD for 8 and 12 weeks. As expected, mice fed an HCD for 8 and 12 weeks had greater total lesion area (Figure $3 \mathrm{~A}$ ). The total lesion areas in the diabetic $\mathrm{Ldlr}^{-/-}$and hAR- $\mathrm{Ldlr^{-/- }}$ mice were $27.7 \% \pm 0.9 \%$ and $39.3 \% \pm 2.8 \%$ at 8 weeks of age and $33.7 \% \pm 3.4 \%$ and $57.9 \% \pm 6.7 \%$ at 12 weeks, respectively. Thus, aortic lesion size increased with longer feeding and at both 8 and 12 weeks was still greater in the hAR-expressing diabetic mice. The lesion size specifically in the aortic arch area was $43.2 \% \pm 4.5 \%$ in $\mathrm{Ldlr}^{-/-}$versus $67.6 \% \pm 3.6 \%$ in hAR$\mathrm{Ldlr}^{-/-}$mice at 8 weeks and $52.4 \% \pm 6.0 \%$ versus $75.9 \pm 1.9 \%$ after 12 weeks of HCD (Figure 3B). Figure 3 shows representative pictures of arch lesion areas (Figure 3C) and pinned out stained aortas (Figure 3D) of the 12-week HCD-fed mice.

$\mathrm{Ldlr}^{+/-}$nondiabetic and diabetic mice with and without hAR expression and fed a cholesterol/cholic acid diet have identical plasma cholesterol levels. In order to examine the effects of hAR expression in a more moderately hyperlipidemic animal model, we induced diabetes in $\mathrm{Ldll}^{+/-}$ mice with and without hAR transgene expression and fed the mice a cholesterol/cholic acid-containing (CCA) diet to enhance atherogenesis. Other investigators have induced atherosclerotic lesions in $L d l r^{+/}$mice by feeding them the CCA diet $(25,26)$. STZ treatment led to an approximately 3 -fold increase in glucose levels. However, CCA diet-fed animals had much lower cholesterol concentrations 

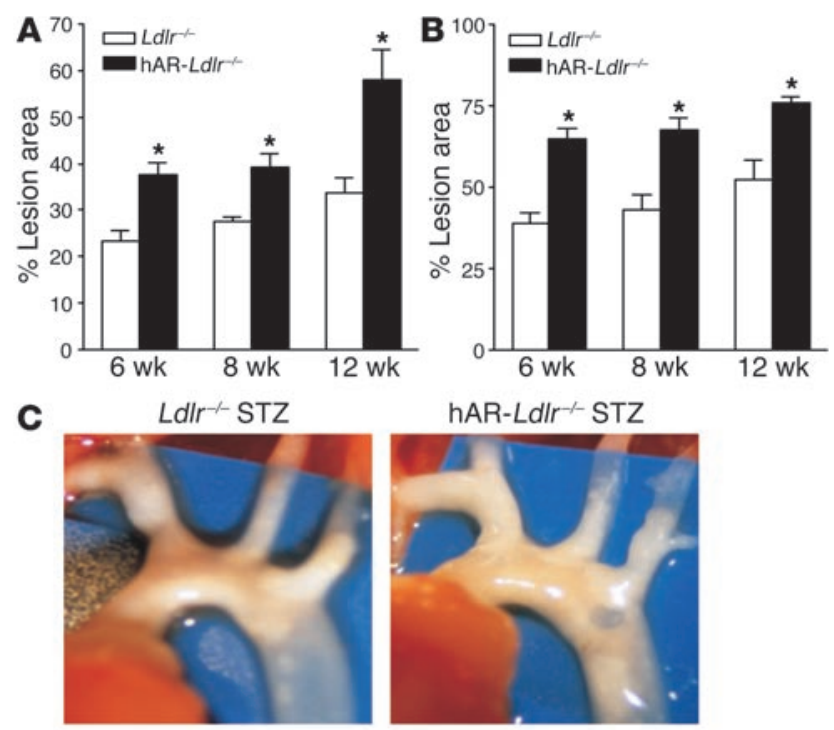

hAR-Ldlr $r^{-}$STZ

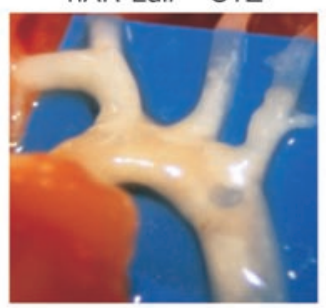

D

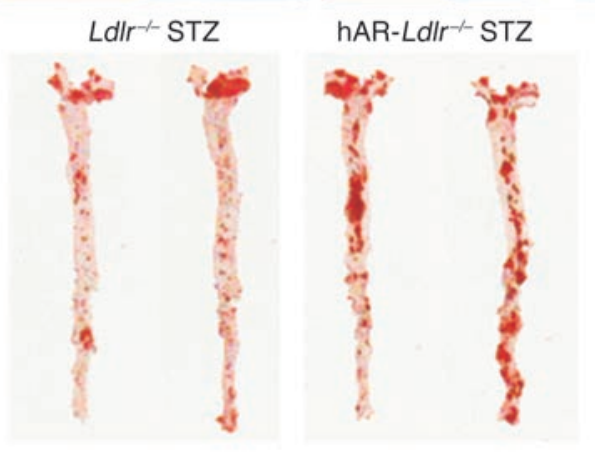

than our HCD-fed $\mathrm{Ldlr}^{-/-}$mice. Diabetic and nondiabetic $\mathrm{Ldlr}^{+/-}$ mice had identical plasma cholesterol levels that averaged approximately $520 \mathrm{mg} / \mathrm{dl}$ and similar triglyceride and HDL levels (Table 2). This allowed us to compare diabetic and nondiabetic animals with similar lipid profiles.

hAR transgene increased lesion size in diabetic Ldlr ${ }^{+/-}$mice. Although all mice had similar lipid profiles, lesion area was greatest in the diabetic hAR-expressing mice. Consistent with the lower cholesterol levels, the mice fed the CCA diet had smaller lesions than did the HCD-fed mice, as shown in Figure 4, A-C. hAR did not alter lesion size in nondiabetic mice. In diabetic mice, total lesion area was doubled by hAR expression $(8.9 \% \pm 1.0 \%$ vs. $16.1 \% \pm 1.9 \%$ of total lesion; Figure 4D). Total lesion size in nondiabetic mice was $8.2 \% \pm 1.0 \%$ in $\mathrm{Ldll}^{+--}$and $7.9 \% \pm 0.9 \%$ in hAR- $\mathrm{Ldlr}^{+/-}$mice. Thus, hAR expression increased atherosclerosis in mice with diabetes, and this was regardless of any changes in plasma lipoprotein levels.

Although lesion area in the aortic arch was also increased by hAR expression, diabetes alone affected this portion of the artery. Lesion area in the arch of diabetic mice was $15.0 \% \pm 2.8 \%$ in $\mathrm{Ldlr}^{+/-}$versus $30.7 \% \pm 4.2 \%$ in hAR- $\mathrm{Ldlr}^{+/-}$ mice (Figure 4E). In nondiabetic mice, aortic arch lesion area was $3.3 \% \pm 0.7 \%$ versus $4.5 \% \pm 1.2 \%$. Therefore, in this region, diabetes intensified disease; however, hAR expression compounded this change.

Quantification and morphology of aortic root lesions. Atherosclerosis was also assessed in tissue sections obtained from

\section{Figure 3}

The atherosclerosis lesion size increased in diabetic mice with increased time period of high-cholesterol feeding. (A) Total lesion area in diabetic $\mathrm{Ldll}^{-1-}$ and $\mathrm{hAR}$-Ldlr $\mathrm{r}^{-/-}$mice after 6, 8, and 12 weeks. (B) Lesion in the aortic arch of diabetic Ldlr ${ }^{-/}$and $\mathrm{hAR}$-Ldlr $r^{-1-}$ mice after 6,8 , and 12 weeks on the HCD. Values are mean \pm SEM of 5-8 mice per group; ${ }^{*} P<0.05$. (C) Aortic arch lesion area in 12-week HCD-fed $L d l r^{--}$and $\mathrm{h} A R-L d l r^{-1-}$ diabetic mice. Magnification, $\times 26$. (D) Oil red O staining of en face lesion area of $L d l r^{--}$and $\mathrm{h} A R-L d l r^{--}$diabetic mice fed the HCD for 12 weeks.

the aortic root. The nondiabetic mice had minimal lesions in the root area, averaging approximately $10,000 \mu \mathrm{m}^{2}$ (Figure 5A). Compared with that in $\mathrm{Ldlr}^{-/-}$mice, the lesion size was markedly increased in the diabetic hAR- $\mathrm{Ldlr}^{-/-}$mice: 88,500 $\pm 16,608 \mu \mathrm{m}^{2}$ versus $171,012 \pm 25,321 \mu \mathrm{m}^{2}$ (Figure $5, \mathrm{~A}$ and $\mathrm{B}$ ). Thus, in the aortic root of CCA diet-fed mice, diabetes alone increased aortic lesion size; however, as in other areas, hAR expression worsened the disease, but only in diabetic animals.

Macrophages from hAR-expressing mice have increased expression of inflammatory markers. We assessed whether hAR expression was present in atherosclerotic lesions. Staining of lesions for AR expression using an anti-hAR polyclonal antibody showed robust hAR transgene expression in the macrophage-rich regions (Figure 6A).

We next studied whether macrophages from hAR-expressing cells differed from those from $\mathrm{Ldlr}^{-/-}$mice in their expression of inflammatory markers. A 12-fold increase in iNOS mRNA and a 5-fold increase in IL-6 mRNA expression were found in peritoneal macrophages obtained from hAR-expressing mice (Figure 6B). No significant differences in expression of ICAM-1, VCAM-1, IFN- $\gamma$, TNF- $\alpha$, and NF- $\kappa B$ were noted.

Macrophages from hAR-expressing mice have greater uptake of modified lipoproteins. Oxidized lipoproteins are internalized by macrophages via CD36 and scavenger receptor-A (SR-A). The mRNA (Figure 7A) and protein levels (Western blot in Figure 7B) of these receptors were increased by hAR expression. The increases in CD36 and SR-A mRNA expression were 1.7- and 2.3-fold, respectively, in the hAR$\mathrm{Ldlr}^{-/-}$mice relative to $\mathrm{Ldlr^{-/- }}$ mice. The protein expression of both these genes was also increased; ATP-binding cassette A1 (ABCA1) protein expression did not appear to be altered.

We then assessed whether macrophages from hAR-transgenic mice internalize more lipoproteins. Uptake of ${ }^{125} \mathrm{I}$-acetyl-LDL ( $\left.{ }^{125} \mathrm{I}-\mathrm{Ac}-\mathrm{LDL}\right)$ was greater in macrophages from hAR- $L d l r^{-/}$than those from $L d l r^{-/-}$mice $(5.27 \pm 0.9$ vs. $1.81 \pm 0.6 \mu \mathrm{g} / \mathrm{mg}$ cell pro-

\section{Table 2}

Blood glucose and lipid profile in male mice fed a CCA diet for 12 weeks

$\begin{array}{lcccc} & \begin{array}{c}\text { Ldlr }{ }^{+-} \\ (\boldsymbol{n}=\mathbf{8})\end{array} & \begin{array}{c}\text { hAR-Ldlr+/- } \\ (\boldsymbol{n}=\mathbf{8})\end{array} & \begin{array}{c}\text { Ldlr }^{+/-} \mathbf{S T Z} \\ (\boldsymbol{n}=\mathbf{1 6})\end{array} & \begin{array}{c}\text { hAR-Ldlr } \boldsymbol{r}^{+/-} \text {STZ } \\ (\boldsymbol{n}=\mathbf{1 2})\end{array} \\ \text { Glucose (mg/dl) } & 127 \pm 9 & 108 \pm 6 & 436 \pm 38^{A} & 420 \pm 34^{A} \\ \text { TC (mg/dl) } & 483 \pm 51 & 530 \pm 33 & 543 \pm 43 & 525 \pm 54 \\ \text { TG (mg/dl) } & 47 \pm 6 & 50 \pm 5 & 49 \pm 4 & 49 \pm 6 \\ \text { VLDL-C (mg/dl) } & 269 \pm 40 & 319 \pm 27 & 318 \pm 34 & 310 \pm 38 \\ \text { LDL-C (mg/dl) } & 106 \pm 10 & 138 \pm 3 & 125 \pm 13 & 147 \pm 10 \\ \text { HDL-C (mg/dl) } & 77 \pm 4 & 63 \pm 7 & 70 \pm 9 & 58 \pm 11\end{array}$

Data are expressed as mean \pm SEM. ${ }^{A} P<0.05$ relative to nondiabetic controls. Lipid measurements were performed in plasma samples from 6-hour fasted mice. Glucose was measured in whole blood using a glucometer. $-\mathrm{C}$, cholesterol. 
A

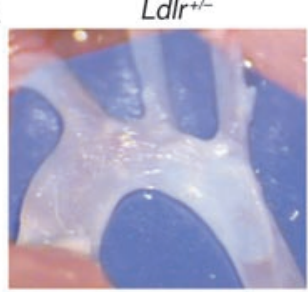

B

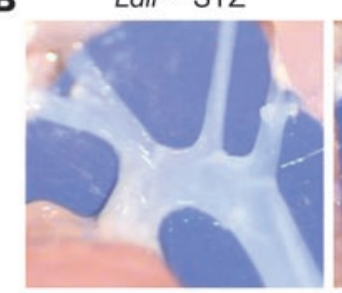

C

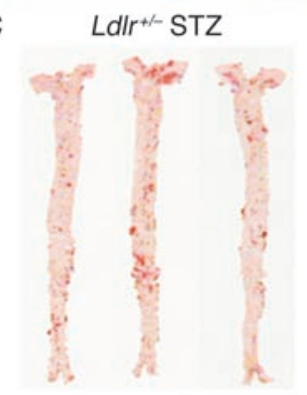

$\mathbf{D}_{40}$

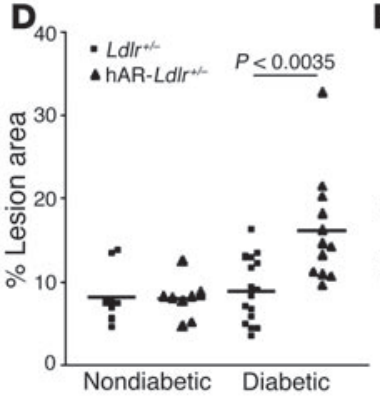

hAR-LdIr+

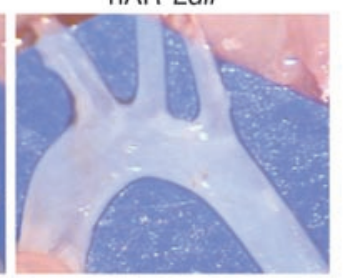

hAR-Ldlr $r^{+/}$STZ

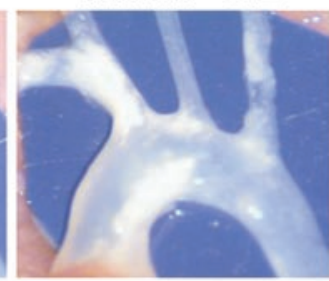

hAR-Ldlr+/ STZ
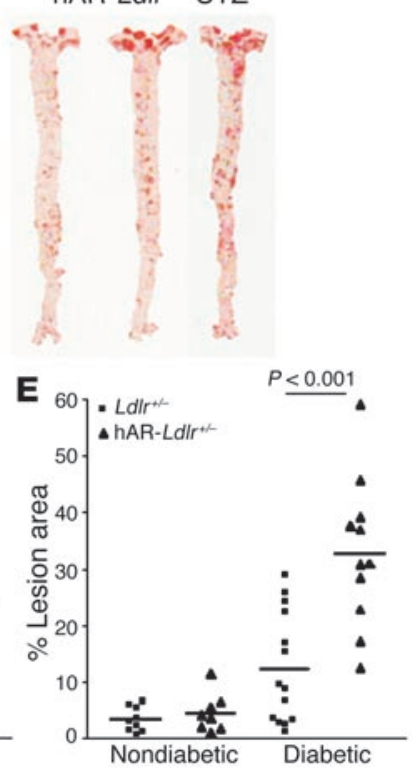

tein; Figure 7C). Therefore, hAR-expressing macrophages appear to have greater potential to acquire lipoproteins that allow for conversion into foam cells.

Aortic gene expression. AR has been postulated to increase ROS production, perhaps due to defective regeneration of glutathione. Aortas were obtained from $L d l r^{-/-}$mice with and without hAR expression. Some mice were treated with STZ, and 4 weeks later while they were still on a chow diet, the vessels were obtained. This was to detect gene changes prior to development of atherosclerosis. Levels of 2 markers of ROS production, glucose 6 phosphate dehydrogenase (G6PD) and glutathione peroxidase (GSH-px), were reduced with diabetes, but further reduced with hAR expression (Figure 8). VCAM-1 expression was increased in both groups of diabetic mice. These data suggest that a combination of diabetes and hAR expression led to a defect in the antioxidant defense system.

\section{Discussion}

Atherosclerosis is caused by lipoprotein retention within the arterial wall followed by inflammation associated with macrophage accumulation (27). Humans with both type 1 and type 2 diabetes

\section{Figure 4}

Diabetic hAR-LdIr+/- mice have greater lesion area than $L d l r^{+/-}$mice fed a CCA diet for 12 weeks. (A) Aortic arch lesion area in $\mathrm{Ldll} \mathrm{r}^{+/-}$and hAR$\mathrm{Ld}_{\mathrm{Ir}}{ }^{+-}$nondiabetic mice. (B) Aortic arch lesion area in Ldlrt/- and hAR$L d l r^{+/-}$diabetic mice. Magnification, $\times 26$. (C) Oil red O staining of en face lesion area in $\mathrm{Ld}_{\mathrm{r}} \mathrm{r}^{+-}$and hAR-Ldlr+/- diabetic mice. (D) Total lesion area in nondiabetic and diabetic $L d l r^{+/-}$and hAR-Ldlr $r^{+/-}$mice (E) Aortic arch lesion area in nondiabetic and diabetic $L d l r^{+/-}$and hAR-Ldlr ${ }^{+/-}$mice.

have an acceleration of this process. Therefore, it is likely that common abnormalities found in both diseases, hyperglycemia and defective insulin actions, are responsible. Efforts to understand the mechanisms by which diabetes accelerates atherosclerosis have led us and others to attempt to create animal models of diabetesinduced atherosclerosis. Several studies have suggested that mice are resistant to the deleterious effects of hyperglycemia (reviewed in ref. 3) and have shown that arterial levels of advanced glycosylation end-products (AGEs) do not correlate with atherosclerosis (9). Results of our current studies suggest that genetic AR deficiency might be 1 reason that mice are relatively resistant to diabetic complications. We show the following. (a) Compared with human tissues, hearts and macrophages from mice had lower expression levels of AR, which were partially restored by introduction of the hAR transgene. (b) $L d l r^{-/-}$mice fed a nondiabetogenic HCD had greater hypercholesterolemia after STZ treatment. hAR expression did not alter plasma lipid levels; however, it increased atherosclerosis in diabetic, but not nondiabetic, mice. (c) CCA diet-fed $\mathrm{Ldlr}^{+/-}$mice had cholesterol levels of approximately $520 \mathrm{mg} / \mathrm{dl}$, and diabetes and hAR expression did not alter plasma cholesterol levels. STZinduced diabetes increased lesion size in hAR- $L d l r^{+/-}$mice. (d) There are several possible mechanisms for this effect. One is increased expression of inflammatory markers and scavenger receptors as well as greater uptake of modified lipoproteins by hAR-expressing mouse macrophages. A second is an alteration in gene expression of aortic enzymes involved in glutathione regeneration.

AR converts glucose to sorbitol, which is then oxidized by sorbitol dehydrogenase to fructose. Previous studies suggested that mice have lower levels of AR protein than do humans $(19,21)$. We confirmed that hearts and macrophages from mice have much lower expression of AR than those from humans. Even in the presence of the ubiquitously expressed hAR transgene, levels of AR mRNA were still lower than those in healthy humans. Thus, hAR expression was not a pharmacologic intervention; rather, it was restorative. It should be noted that there are other genetic variations in mice that make it difficult to recreate human pathophysiology in them. One such defect that relates to diabetic complications is the lack of angiopoietin-like protein 3 in some mouse strains that do not develop diabetes-induced hypertriglyceridemia (28).

Understanding the effects of diabetes on atherosclerosis in $\mathrm{HCD}$-fed $\mathrm{Ldlr}^{-/}$mice was complicated by the fact that they developed more dyslipidemia. Nonetheless, lesion area was increased in diabetic mice expressing hAR compared with diabetic mice with similar cholesterol levels not expressing this transgene. Consistent with the hypothesis that AR repletion is required in order for hyperglycemia to have toxic effects, hAR expression did not alter atherosclerosis in nondiabetic mice. These data are most compatible with those in the recent report of Renard et al. (8) who studied mice in which a virus had destroyed pancreatic islets and that were fed diets with variable amounts of cholesterol. Plasma cholesterol, and not glucose, was primarily responsible for greater lesion area. 
A

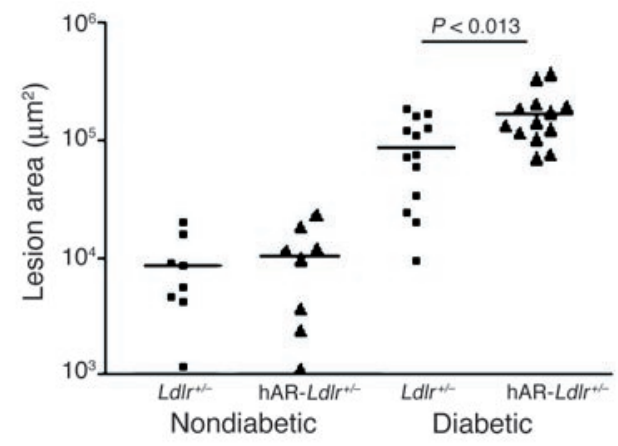

B

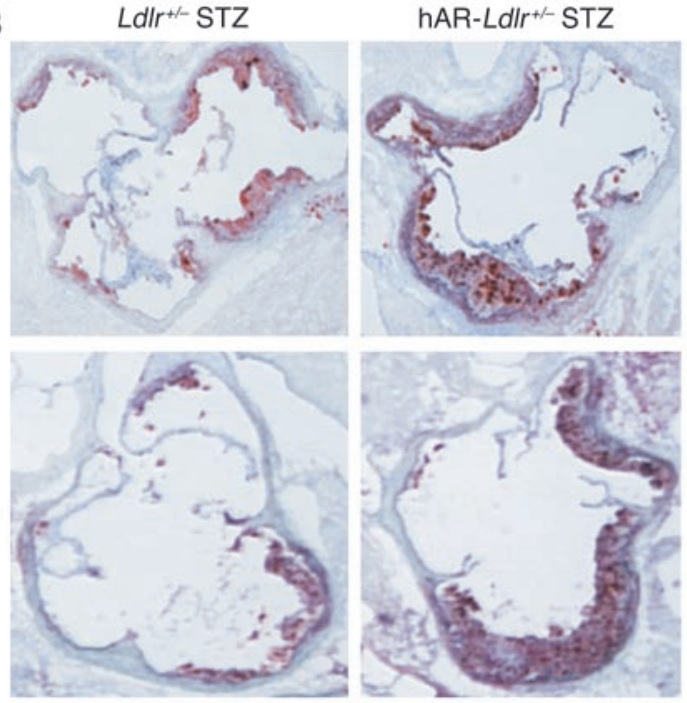

However, even in mice without marked increases in atherosclerosis, this group found greater amounts of hemorrhage into advanced lesions in diabetic mice. This suggests that diabetes might have several toxic effects, including (a) increased lesion size in genetically susceptible animals and (b) greater plaque instability.

The effects of both the hAR transgene and STZ treatment were evident in studies of CCA diet-fed $\mathrm{Ldlr}^{+/-}$mice. Total lesion area was similar in nondiabetic and STZtreated animals, and hAR increased lesion size in the diabetic mice. However, aortic root lesions were greater in diabetic mice, even without hAR expression, though hAR increased the lesion size even more. This cholic acid-containing diet is known to increase inflammation

\section{Figure 6}

hAR-expressing mice have more AR protein expression in the atherosclerotic lesion area compared with nontransgenic mice. iNOS and IL-6 increased several folds in peritoneal macrophages from hAR-Ldlr ${ }^{-1-}$ compared with those from Ldlr ${ }^{-1-}$ mice. (A) Immunohistochemical staining of aortic root sections of $L d l r^{-1-}$ and hAR-Ldlr $r^{-1-}$ diabetic mice for AR protein using hAR antibody. "Negative" indicates staining after use of nonimmune serum. Magnification, $\times 200$. (B) Real-time PCR gene expression of iNOS, IL-6, ICAM-1, VCAM-1, IFN- $\gamma$, TNF- $\alpha$, and NF- $\kappa B$ in peritoneal macrophages from $L d l r^{-1-}$ and hAR-Ldlr ${ }^{-1}$ mice. Values were normalized to $\beta$-actin and expressed as mean \pm SEM. Data are from experiments performed in duplicate on an average of 8 mice. ${ }^{*} P<0.05$.
A

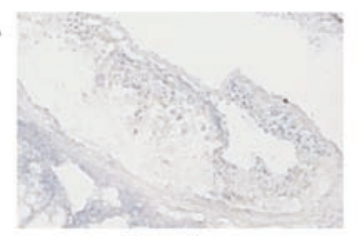

Negative

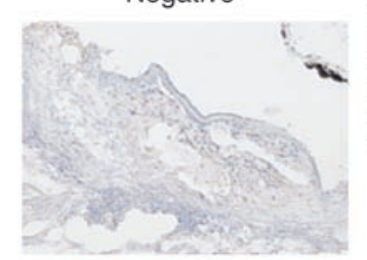

Ldlr $r^{-1-}$

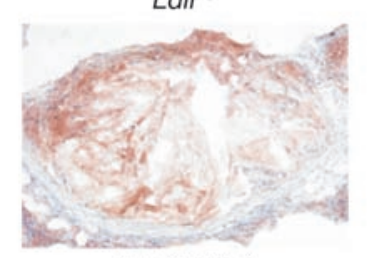

hAR-Ldlr-1-
B

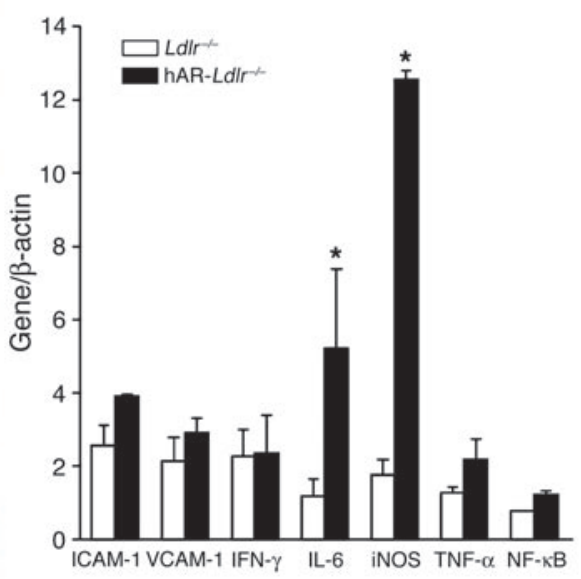



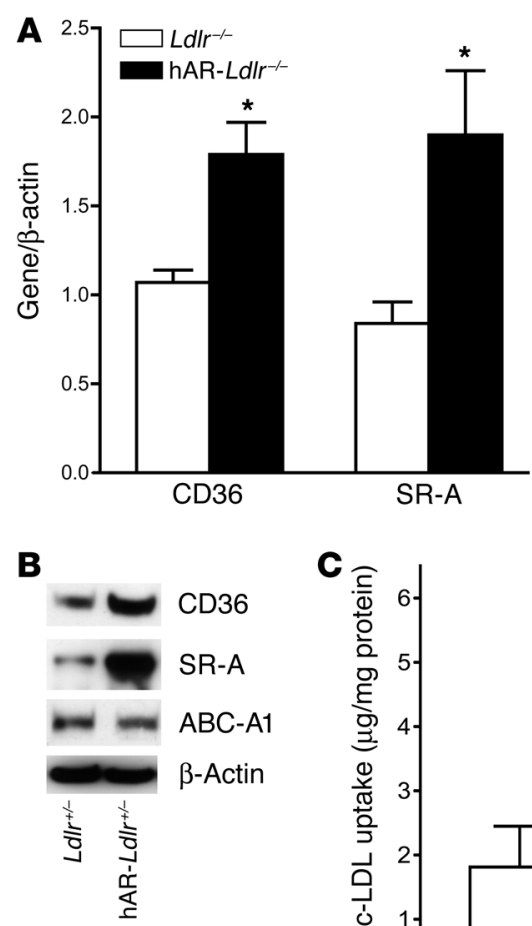

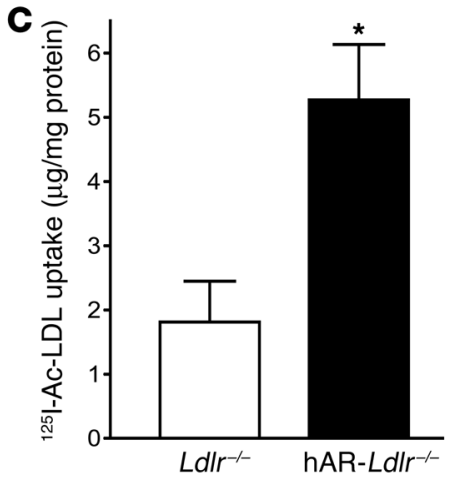

appear to have greater potential to acquire lipoproteins that allow for conversion into foam cells. A recent article by Fukuhara-Takaki et al. (38) reported increased SR-A expression and enhanced uptake of Ac-LDL and oxidized LDL in human macrophages under highglucose conditions and increased ROS generation. Increased expression of receptors for modified lipoproteins has also been associated with defective insulin signaling (39).

There are a number of other postulated mechanisms whereby the actions of AR might affect atherosclerotic lesion formation. Foremost of these hypotheses suggests that AR leads to glutathione depletion (reviewed in ref. 40). For this reason, we assessed the expression of several oxidant stress enzymes in the aortas of mice prior to the development of atherosclerosis. Expression of G6PD and GSH-px, 2 enzymes that assist with the regeneration of glutathione, was reduced with the combination of diabetes and hAR expression. Specifically, the reduction in GSH-px has significant bearing on the generation of ROS by mitochondria. GSHpx catalyzes the conversion of hydrogen peroxide to water in the mitochondria. Reduced activity of GSH-px would result in increases in levels of peroxidase and/or hydroxyl radicals, thus increasing mitochondrial oxidant stress. The reduction in cytosolic G6PD

\section{Figure 8}

Aortic gene changes prior to atherosclerosis. Aortas were obtained from Ldlr-/- and hAR-Ldlr ${ }^{-/-}$mice either left untreated (control) or made diabetic by STZ injection. There were 4-6 aortas in each of the 4 groups. The STZ treatment occurred 4 weeks earlier, and the mice remained on a chow diet. Gene expression was assessed by realtime PCR. ${ }^{*} P<0.05$ versus control. G6PD and GSH-px mRNA levels in STZ-treated hAR-LdIr - $^{-1}$ aortas were also significantly reduced $(P<0.05)$ compared with those in STZ-treated Ldlr ${ }^{-/-}$aortas.

\section{Figure 7}

Expression of modified lipoprotein receptors and uptake of Ac-LDL are increased in peritoneal macrophages. (A) mRNA expression of CD36 and SR-A by real-time PCR in peritoneal macrophages from $\mathrm{LdIr}^{--}$and hAR-Ldlir-- mice. Values were normalized to $\beta$-actin and expressed as mean \pm SEM. Data are from experiments performed in duplicate on an average of 8 mice. (B) Western blot analysis of CD36, SR-A, and ATP-binding cassette $A 1$ (ABCA1) protein in peritoneal macrophages from hAR-Ldlr $r^{-1-}$ and $L d l r^{-1-}$ mice. Data are from pooled macrophages collected from 3 mice per group. (C) Uptake of $125 /-A c-L D L ~(100 \mu \mathrm{g} / \mathrm{ml})$ in peritoneal macrophages from $L d l r^{-/-}$and hAR-Ldlr $r^{-1-}$ mice. Values are expressed as mean \pm SEM. Data are from experiments performed in duplicate on 6 mice. ${ }^{*} P<0.05$.

and mitochondrial GSH-px are indicative of the high oxidant stress environment in aortas of hAR-expressing mice. Therefore, it is likely that these vessels have abnormal response to reactive oxygen. Further investigations to define the in vivo processes that are altered by the hAR transgene are in progress.

Our data suggest that hyperglycemia by itself promotes atherosclerosis in a setting of increased hAR expression. The development of accelerated vascular disease in diabetes may be explained by glucose flux through either the polyol or hexosamine pathways, greater production of AGEs, and activation of PKC. Brownlee has suggested that in the setting of hyperglycemia, cellular superoxide production accelerates each of these potentially toxic processes (12). Thus, although our data show that increased AR expression accelerates atherosclerosis in diabetic mice, it is possible that activation of any of the known pathways for diabetic complications might have a similar effect. Most important for understanding diabetic vascular disease, our results confirm that in vitro effects found with a potentially toxic pathway can be shown to increase disease in animals. Moreover, we have created a model of macrovascular disease that can be used to test therapeutic agents altering $\mathrm{AR}$ or its downstream effects.
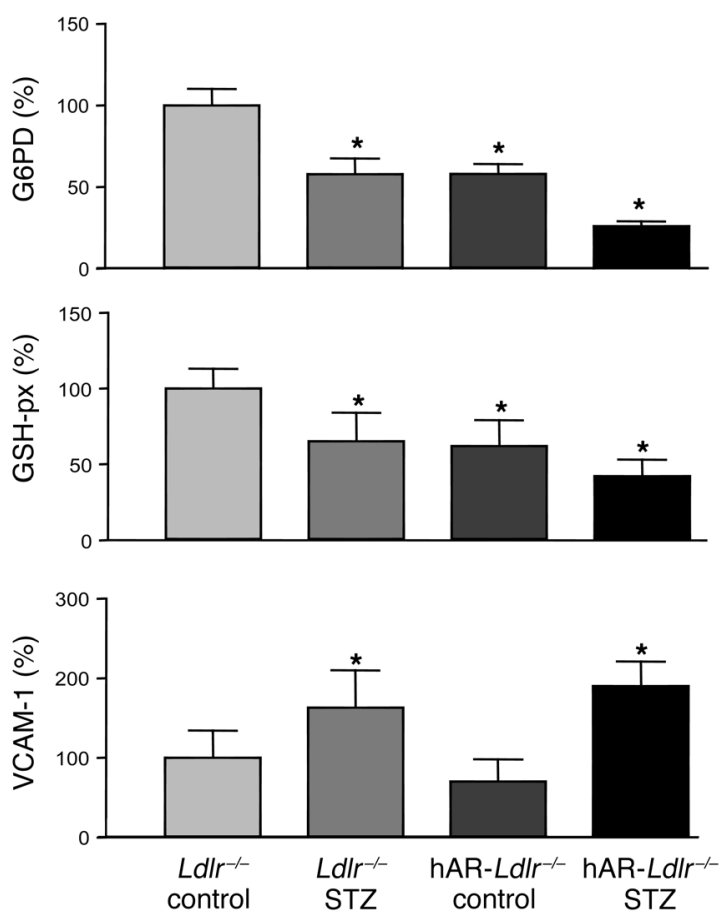
Our observations have implications for assessment of macrovascular disease risk in humans. They suggest that gene expression of AR might modify toxic reaction to hyperglycemia. One possibility is that humans who are relatively deficient in AR expression are less likely to develop macrovascular diabetic complications. Polymorphisms in the promoter region as well as elsewhere in the AR gene have been associated with susceptibility to nephropathy, retinopathy, and diabetic neuropathy. These associations have been replicated in patients with either type 1 or type 2 diabetes mellitus as well as across ethnic groups (41). It has also been reported that diabetes leads to increased AR expression (42) and that this upregulation of the AR pathway is possibly harmful. If, as suggested by our data, hyperglycemia increases atherosclerosis via actions of AR, inhibition of AR could be useful in the treatment of diabetic atherosclerosis. Most important, our data confirm the long-held belief that hyperglycemia is toxic to large arteries.

\section{Methods}

Mice, diets, and induction of diabetes. $\mathrm{Ldll}^{-/-}$mice on a C57BL/6 background (B6.129S7-LDlr ${ }^{\text {tm1Her; }}$ stock no. 002207) were purchased from the Jackson Laboratory. Mice transgenic for hAR were obtained from M. Itakura (University of Tokushima, Tokushima, Japan), and a colony was established at Columbia University. The hAR-transgenic mice were developed by injecting full-length hAR cDNA with a mouse major histocompatibility antigen class I promoter $(22,43)$. PCR was used for genotyping for loss of the $L d l r$ (44) and the presence of the hAR transgene as described previously (19). Mice were maintained in a temperature-controlled $\left(25^{\circ} \mathrm{C}\right)$ facility with a 12-hour light/12-hour dark cycle and given free access to food and water, except when fasting blood specimens were obtained. Mice were fed either laboratory rodent chow (PMI Nutrition International), semisynthetic modified AIN76 diet containing 0.15\% cholesterol (45) (HCD), or a diet containing CCA (46). The Institutional Animal Care and Use Committee of Columbia University approved all animal protocols.

hAR-transgenic mice on a C57BL/ 6 background were crossed with $L d l r^{-/-}$mice to obtain hAR- $L d l r^{-/-}$and hAR- $L d l r^{+/-}$mice. All the mice were hemizygous for the hAR transgene. hAR- $L d l r^{-/-}$, hAR- $L d l r^{+/-}, L d l r^{-/}$, and $L d l r^{+/-}$mice of 8 weeks age were divided into 2 groups. One-half of the mice were made diabetic by administration of $50 \mathrm{mg} / \mathrm{kg}$ body weight STZ intraperitoneally for 5 days, and the other half were used as nondiabetic controls. Only male mice were used for these studies. Four weeks after STZ administration, diabetic and nondiabetic mice on the $\mathrm{Ldl}^{+/}$- background were kept on the CCA diet for 12 weeks. $\mathrm{Ldlr}^{-/-}$mice were fed the HCD for 6,8 , and 12 weeks.

Blood sampling. Plasma samples were obtained from 6-hour fasted mice after 6,8 , or 12 weeks of HCD feeding, or at the end of 12 weeks for the mice on the CCA diet. Glucose was measured directly from the tail tip with a glucometer; total cholesterol and triglyceride levels were measured enzymatically using kits from Wako Chemicals USA. Lipoproteins, VLDL $(d<1.006 \mathrm{~g} / \mathrm{ml})$, IDL plus LDL $(d=1.006-1.063 \mathrm{~g} / \mathrm{ml})$, and HDL $(d=1.063-1.21 \mathrm{~g} / \mathrm{ml})$, were separated by sequential density ultracentrifugation of plasma in a TLA100 rotor (Beckmann Coulter) (10).

Tissue collection. Mice were sacrificed at different time points. Hearts were perfused with $10 \mathrm{ml}$ cold PBS. Tissues surrounding the aorta were cleared under a binocular microscope. The heart was removed by cutting the descending aorta halfway between the aortic root and the brachiocephalic artery and frozen in OCT compound (Tissue-Tek; Sakura Finetek USA Inc.). The remaining aorta was dissected to the iliac bifurcation, opened longitudinally, and fixed between 2 glass slides.

Western blotting of aortic AR. SDS-PAGE was performed on a $12 \%$ acrylamide gel using a Novex XCell II electrophoresis apparatus (Invitrogen
Corp.). Proteins were stained with Coomassie blue (Bio-Rad Laboratories). For immunoblot analysis, after the electrophoresis, the proteins were transferred onto the nitrocellulose membrane Protran (Schleicher \& Schuell BioScience Inc.) in Tris-glycine buffer, pH 8.3, containing 20\% (vol/ vol) methanol at $25 \mathrm{mV}$ for 90 minutes using a Novex XCell II Blot Module (Invitrogen Corp.). Nonspecific binding of the membrane was blocked with $5 \%$ nonfat dry milk (Bio-Rad Laboratories). The membrane was incubated in PBS containing polyclonal antibody against hAR at $4^{\circ} \mathrm{C}$ overnight and then further incubated in PBS containing anti-goat IgG coupled with HRP. The immunostaining of AR was visualized with $4 \mathrm{CN}$ as substrate (Kirkegaard and Perry Laboratories Inc.).

AR gene expression by Northern blot analysis. Total RNA from the ventricles was isolated using the TRIzol reagent (Invitrogen Corp.). RNA $(10 \mu \mathrm{g})$ was separated on a $1 \%$ agarose gel containing formaldehyde and transferred to a nylon filter (Hybond- $\mathrm{N}^{+}$) for Northern blotting. We used probes for hAR and mAR. The primer sequences were: hAR (S), 5'-GAAGGAATTTTTCCCATTGG-3'; hAR (AS), 5'-GACTGGCAGTACTGGATTAA-3' (NCBI nucleotide sequence number J04795); mAR (S), 5'-CTCAGGGAACGTGATACCTA3'; mAR (AS), 5'-TGTTTGGCACAGCTCATCAAG-3' (NCBI nucleotide sequence number D32250). Results were normalized to GAPDH, which can detect both the human- and mouse-specific gene.

Quantitative atherosclerosis analysis. Mice were killed at the ages indicated in the figures, and atherosclerosis assays were performed. At the time of sacrifice, the aortic arch and distributing vessels were photographed. The aortas were removed, cut open, fixed in $10 \%$ buffered formalin, and stained with oil red $\mathrm{O}$. En face lesion area of the aorta was quantified relative to its surface area using ImagePro Plus software (version 4.1.0.0; Media Cybernetics).

Atherosclerosis assays on the aortic roots were performed as described previously (10). In brief, hearts were perfused with PBS, embedded in OCT compound, sectioned at $10-\mu \mathrm{m}$ thickness in a cryostat, and fixed in $10 \%$ buffered formalin for 15 minutes and allowed to dry at room temperature for 30 minutes. Sections were stained with oil red $\mathrm{O}$ and hematoxylin and counterstained with light green, and lesions of the proximal aorta were measured in $80-\mu \mathrm{m}$ intervals using ImagePro Plus software. The mean lesion area of 6 sections was calculated and expressed as micrometers squared.

Isolation of peritoneal macrophages. Peritoneal macrophages from 2month-old male $L d l r^{-/-}$and hAR-Ldlr $r^{-/-}$mice were harvested 3 days after intraperitoneal injection of $40 \mu \mathrm{g}$ concanavalin A in $0.5 \mathrm{ml}$ sterile PBS. Cells were seeded in 6-well plates for RNA isolation, and for the uptake studies, cells were seeded in 12-well plates. The isolated cells were incubated in $5 \mathrm{mM}$ glucose containing DMEM supplemented with 10\% FBS and $20 \% \mathrm{~L}$ cell-conditioned medium. Before isolation of RNA, the cells were washed with PBS to remove any excess medium, and cells were scraped from the plate in PBS and pelleted.

Monocyte-enriched cell preparations were isolated from the blood of healthy volunteers as described previously (47) after their informed consent and approval by the Columbia University Medical Center Institutional Review Board were obtained. The monocytes were plated on $75-\mathrm{mm}$ flasks in DMEM containing 10\% FBS medium and allowed to differentiate for 5 days. Processing of human macrophages was similar to that for mouse macrophages.

Quantitative real-time PCR for macrophage AR and inflammation genes. Total RNA was isolated from macrophages using an RNeasy Mini Kit (QIAGEN). RNA for real-time PCR was quantified using RiboGreen RNA quantitation reagent (catalog no. R-11490; Invitrogen Corp.). The mRNA levels for hAR, mAR, ICAM-1, VCAM-1, IFN- $\gamma$, IL-6, iNOS, TNF- $\alpha$, NF- $\kappa B$, SR-A, and CD36 were determined by SYBR green (Applied Biosystems) realtime PCR using $10 \mathrm{ng}$ of total RNA. The primer sequences were: hAR, (S) 5'-AGTCGGGCAATGTGGTTCCC-3', (AS) 5'-GGATTAACTTCTCCTGAGTG-3'; mAR, (S) 5'-CCTCAGGGAACGTGATACCT-3', (AS) 5'-CAAT- 
CAGCTTCTCCTGAGTT-3'; ICAM-1, (S) 5'-CGTGTATTCGTTTCCGG-3', (AS) 5'-CGGCATGAGAAATTGGC-3'; VCAM-1, (S) 5'-TTGCCTCGCTAGGTTAC-3', (AS) 5'-CCGGAATCGTCCCTTT-3'; IFN- $\gamma$, (S) 5'-CTATTTTAACTCAAGTGGC-3', (AS) 5'-GTGGGTTGTTGACCTCA-3'; IL-6, (S) 5'CCCAACAGACCTGTCT-3', (AS) 5'-CCAGTTTGGTAGCATCC-3'; iNOS, (S) 5'-AACCCAAGGTCTACGT-3', (AS) 5'-GGAAAAGACTGCACCG-3'; TNF- $\alpha$, (S) 5'-CACAGAAAGCATGATCCG-3', (AS) 5'-GGCTACAGGCTTGTCAC-3'; NF-кB, (S) 5'-GCCCTAAAGATTGTGCCA-3', (AS) 5'-CACTGCGTAGTCGAAAAG-3'; SR-A, (S) 5'-GGAGTGTAGGCGGATC-3', (AS) 5'-GTCAATGGAGGCCCCA-3'; CD36, (S) 5'-CAGTCGGAGACATGCT-3', (AS) 5 '-CTCGGGGTCCTGAGTT-3'; $\beta$-actin, (S) 5'-TGAAGTGTGACGTTGACA-3', (AS) 5'-TAGAAGCACTTGCGGTGCACGATGGAG-3'; mG6PD, (S) 5'-GTGGGAGCCAGATGCACTTT-3', (AS) 5'-CAGAAAGGGTGGCCAGAAGA-3'; mGSH-px, (S) 5'-CGTGCAATCAGTTCGGACAC-3', (AS) 5'-GCATTCCGCAGGAAGGTAAA-3'. Real-time PCR standard curves were constructed using serial dilutions of mouse total RNA isolated from peritoneal macrophages. Cycling parameters were 1 cycle at $95^{\circ} \mathrm{C}$ for 10 minutes, 40 cycles at $95^{\circ} \mathrm{C}$ for 30 seconds, 40 cycles at $60^{\circ} \mathrm{C}$ for 40 seconds, and 40 cycles at $72^{\circ} \mathrm{C}$ for 30 seconds. All values obtained were normalized to mouse $\beta$-actin.

Western blotting. Western blot analysis using total lysates $(25 \mu \mathrm{g})$ from peritoneal macrophages was performed as described previously (38) with primary antibodies against CD36 (dilution 1:2,000; Santa Cruz Biotechnology Inc.), SR-A (dilution 1:2,000; Trans Genic Inc.), ABCA1 (dilution 1:1,000; Novus Biologicals Inc.), or $\beta$-actin (dilution 1:8,000; Sigma-Aldrich).

Immunohistochemical staining for aortic AR. Aortas from $\mathrm{Ldlr}^{-/}$and hAR- $\mathrm{Ldll} \mathrm{r}^{-/}$ mice fed the HCD for 6 weeks were embedded in OCT and snap-frozen in dry ice. Ten-micrometer frozen sections were fixed in cold acetone, and endogenous peroxidase was quenched with $3 \% \mathrm{H}_{2} \mathrm{O}_{2} /$ methanol. The sections were then stained with 1:100 antibody dilution against hAR or CD68 at $37^{\circ} \mathrm{C}$ for 1 hour. Polyclonal antibody against hAR raised in rabbit was a gift from M. Takahashi (Osaka University Medical School, Osaka, Japan).
The antibody was detected with the standard ABC method (Vector Laboratories) and AEC (Zymed Laboratories Inc.) as substrate. Positive staining is shown as red colored deposits. For negative control, sections were incubated with nonimmune rat IgG (Sigma-Aldrich) in place of primary antibody.

Ac-LDL uptake in peritoneal macrophages. Peritoneal macrophages were plated in 12 -well plates at a density of $1 \times 10^{6}$ cells/well and allowed to grow for 24 hours (48). The medium in the confluent plate was changed to DMEM/0.2\% BSA medium containing $100 \mu \mathrm{g}$ of ${ }^{125} \mathrm{I}-\mathrm{Ac}$-LDL (specific activity, $0.254 \mu \mathrm{Ci} / \mu \mathrm{g}$; Biomedical Technologies Inc.) with unlabeled AcLDL $\left(2 \mathrm{mg} / \mathrm{ml}\right.$ stock; Biomedical Technologies Inc.) for 5 hours at $37^{\circ} \mathrm{C}$. For measurement of nonspecific uptake, the cells were incubated with $500 \mu \mathrm{g} / \mathrm{ml}$ of unlabeled Ac-LDL. At the end of 5 hours, the wells were washed and cells lysed with $0.1 \mathrm{~N} \mathrm{NaOH}$ and used for counting. Values are expressed as $\mu \mathrm{g} / \mathrm{mg}$ cell protein.

Statistical analysis. Statistical analyses were done by unpaired 1-tailed Student's $t$ test or ANOVA. All data are expressed as mean \pm SEM, with a statistically significant difference defined as a value of $P<0.05$.

\section{Acknowledgments}

These studies were funded in part by grants U01-HL70524 (AMDCC) and HL56984 (Specialized Center of Research). The authors thank Mitsuo Itakura for providing the hAR mice. We wish to thank M. Brownlee and Jan Breslow for helpful suggestions and critique of some of our data.

Received for publication February 21, 2005, and accepted in revised form June 24, 2005.

Address correspondence to: Ira J. Goldberg, Department of Medicine, Columbia University, 630 West 168th Street, New York, New York 10032, USA. Phone: (212) 305-5961; Fax: (212) 305-5384; E-mail: ijg3@columbia.edu.
1. Anonymous. 1998. Intensive blood-glucose control with sulphonylureas or insulin compared with conventional treatment and risk of complications in patients with type 2 diabetes (UKPDS 33). UK Prospective Diabetes Study (UKPDS) Group. Lancet. 352:837-853.

2. Diabetes Control and Complications Trial. 1995 Effect of intensive diabetes management on macrovascular events and risk factors in the Diabetes Control and Complications Trial. Am. J. Cardiol. 75:894-903.

3. Goldberg, I.J. 2004. Why does diabetes increase atherosclerosis? I don't know! J. Clin. Invest. 114:613-615. doi:10.1172/JCI200422826.

4. Mathe, D. 1995. Dyslipidemia and diabetes: animal models [review]. Diabete Metab. 21:106-111.

5. Keren, P., et al. 2000. Effect of hyperglycemia and hyperlipidemia on atherosclerosis in LDL receptordeficient mice: establishment of a combined model and association with heat shock protein $65 \mathrm{immu-}$ nity. Diabetes. 49:1064-1069.

6. Hasty, A.H., et al. 2001. Severe hypercholesterolemia, hypertriglyceridemia, and atherosclerosis in mice lacking both leptin and the low density lipoprotein receptor. J. Biol. Chem. 276:37402-37408.

7. Park, L., et al. 1998. Suppression of accelerated diabetic atherosclerosis by the soluble receptor for advanced glycation endproducts. Nat. Med. 4:1025-1031.

8. Renard, C.B., et al. 2004. Diabetes and diabetesassociated lipid abnormalities have distinct effects on initiation and progression of atherosclerotic lesions. J. Clin. Invest. 114:659-668. doi:10.1172/ JCI200417867.

9. Reaven, P., Merat, S., Casanada, F., Sutphin, M., and Palinski, W. 1997. Effect of streptozotocin-induced hyperglycemia on lipid profiles, formation of advanced glycation endproducts in lesions, and extent of atherosclerosis in LDL receptor-deficient mice. Arterioscler. Thromb. Vasc. Biol. 17:2250-2256.

10. Kako, Y., et al. 1999. Streptozotocin-induced diabetes in human apolipoprotein B transgenic mice. Effects on lipoproteins and atherosclerosis. J. Lipid Res. 40:2185-2194.

11. Merat, S., Casanada, F., Sutphin, M., Palinski, W., and Reaven, P.D. 1999. Western-type diets induce insulin resistance and hyperinsulinemia in LDL receptor-deficient mice but do not increase aortic atherosclerosis compared with normoinsulinemic mice in which similar plasma cholesterol levels are achieved by a fructose-rich diet. Arterioscler. Thromb. Vasc. Biol. 19:1223-1230.

12. Brownlee, M. 2001. Biochemistry and molecular cell biology of diabetic complications. Nature. 414:813-820.

13. Pfeifer, M.A., Schumer, M.P., and Gelber, D.A. 1997. Aldose reductase inhibitors: the end of an era or the need for different trial designs? [review]. Diabetes. 46(Suppl. 2):S82-S89.

14. Martyn, C.N., Reid, W., Young, R.J., Ewing, D.J., and Clarke, B.F. 1987. Six-month treatment with sorbinil in asymptomatic diabetic neuropathy. Failure to improve abnormal nerve function. Diabetes. 36:987-990

15. Bril, V., and Buchanan, R.A. 2004. Aldose reductase inhibition by AS-3201 in sural nerve from patients with diabetic sensorimotor polyneuropathy. Diabetes Care. 27:2369-2375.

16. Gabbay, K.H. 2004. Aldose reductase inhibition in the treatment of diabetic neuropathy: where are we in 2004? [review]. Curr. Diab. Rep. 4:405-408.

17. Ramasamy, R., Oates, P.J., and Schaefer, S. 1997. Aldose reductase inhibition protects diabetic and nondiabetic rat hearts from ischemic injury. Diabetes. 46:292-300.

18. Johnson, B.F., et al. 2004. Cardiac abnormalities in diabetic patients with neuropathy: effects of aldose reductase inhibitor administration. Diabetes Care. 27:448-454.

19. Hwang, Y.C., et al. 2004. Central role for aldose reductase pathway in myocardial ischemic injury. FASEB J. 18:1192-1199.

20. Markus, H.B., Raducha, M., and Harris, H. 1983. Tissue distribution of mammalian aldose reductase and related enzymes. Biochem. Med. 29:31-45.

21. Tanimoto, T., Maekawa, K., Okada, S., and YabeNishimura, C. 1998. Clinical analysis of aldose reductase for different diagnosis of the pathogenesis of diabetic complication. Anal. Chim. Acta. 365:285-292.

22. Yamaoka, T., et al. 1995. Acute onset of diabetic pathological changes in transgenic mice with human aldose reductase cDNA. Diabetologia. 38:255-261.

23. Hwang, Y.C., et al. 2002. Aldose reductase activation is a key component of myocardial response to ischemia. FASEB J. 16:243-245.

24. Kako, Y., Masse, M., Huang, L.S., Tall, A.R., and Goldberg, I.J. 2002. Lipoprotein lipase deficiency and CETP in streptozotocin-treated apoB-expressing mice. J. Lipid Res. 43:872-877.

25. Arai, T., Wang, N., Bezouevski, M., Welch, C., and Tall, A.R. 1999. Decreased atherosclerosis in heterozygous low density lipoprotein receptor- 
deficient mice expressing the scavenger receptor BI transgene. J. Biol. Chem. 274:2366-2371.

26. van Haperen, R., et al. 2002. Increased risk of atherosclerosis by elevated plasma levels of phospholipid transfer protein. J. Biol. Chem. 277:48938-48943.

27. Khalil, M.F., Wagner, W.D., and Goldberg, I.J. 2004. Molecular interactions leading to lipoprotein retention and the initiation of atherosclerosis [review]. Arterioscler. Thromb. Vasc. Biol. 24:2211-2218.

28. Koishi, R., et al. 2002. Angptl3 regulates lipid metabolism in mice. Nat. Genet. 30:151-157.

29. Vergnes, L., Phan, J., Strauss, M., Tafuri, S., and Reue, K. 2003. Cholesterol and cholate components of an atherogenic diet induce distinct stages of hepatic inflammatory gene expression. J. Biol. Chem. 278:42774-42784.

30. Waller, B.F., Palumbo, P.J., Lie, J.T., and Roberts, W.C. 1980. Status of the coronary arteries at necropsy in diabetes mellitus with onset after age 30 years. Analysis of 229 diabetic patients with and without clinical evidence of coronary heart disease and comparison to 183 control subjects. Am.J. Med. 69:498-506.

31. Luoma, J.S., et al. 1998. Expression of extracellular SOD and iNOS in macrophages and smooth muscle cells in human and rabbit atherosclerotic lesions: colocalization with epitopes characteristic of oxidized LDL and peroxynitrite-modified proteins [review]. Arterioscler. Thromb. Vasc. Biol. 18:157-167.

32. Luoma, J.S., and Yla-Herttuala, S. 1999. Expression of inducible nitric oxide synthase in macrophages and smooth muscle cells in various types of human atherosclerotic lesions. Virchows Arch. 434:561-568.

33. Seino, Y., et al. 1994. Interleukin 6 gene transcripts are expressed in human atherosclerotic lesions. Cytokine. 6:87-91.

34. Sukovich, D.A., et al. 1998. Expression of interleukin-6 in atherosclerotic lesions of male ApoEknockout mice: inhibition by 17 beta-estradiol. Arterioscler. Thromb. Vasc. Biol. 18:1498-1505.

35. Schieffer, B., et al. 2004. Impact of interleukin-6 on plaque development and morphology in experimental atherosclerosis. Circulation. 110:3493-3500.

36. Endemann, G., et al. 1993. CD36 is a receptor for oxidized low density lipoprotein. J. Biol. Chem. 268:11811-11816.

37. Linton, M.F., and Fazio, S. 2001. Class A scavenger receptors, macrophages, and atherosclerosis. Curr. Opin. Lipidol. 12:489-495.

38. Fukuhara-Takaki, K., Sakai, M., Sakamoto, Y.I., Takeya, M., and Horiuchi, S. 2004. Expression of class A scavenger receptor is enhanced by high glucose in vitro and under diabetic conditions in vivo: one mechanism for an increased rate of atherosclerosis in diabetes. J. Biol. Chem. 280:3355-3364.

39. Liang, C.P., et al. 2004. Increased CD36 protein as a response to defective insulin signaling in macrophages. J. Clin. Invest. 113:764-773. doi:10.1172/ JCI200419528.

40. Vincent, A.M., Russell, J.W., Low, P., and Feldman, E.L. 2004. Oxidative stress in the pathogenesis of diabetic neuropathy. Endocr. Rev. 25:612-628.

41. Demaine, A.G. 2003. Polymorphisms of the aldose reductase gene and susceptibility to diabetic microvascular complications. Curr. Med. Chem. 10:1389-1398.

42. Ii, S., et al. 2004. Redox state-dependent and sorbitol accumulation-independent diabetic albuminuria in mice with transgene-derived human aldose reductase and sorbitol dehydrogenase deficiency. Diabetologia. 47:541-548.

43. Nishimura, C., et al. 1990. Cloning and expression of human aldose reductase. J. Biol. Chem. 265:9788-9792.

44. Gaw, A., Mancini, F.P., and Ishibashi, S. 1995. Rapid genotyping of low density lipoprotein receptor knockout mice using a polymerase chain reaction technique. Lab. Anim. 29:447-449.

45. Teupser, D., Persky, A.D., and Breslow, J.L. 2003. Induction of atherosclerosis by low-fat, semisynthetic diets in LDL receptor-deficient $\mathrm{C} 57 \mathrm{BL} / 6 \mathrm{~J}$ and $\mathrm{FVB} / \mathrm{NJ}$ mice: comparison of lesions of the aortic root, brachiocephalic artery, and whole aorta (en face measurement). Arterioscler. Thromb. Vasc. Biol. 23:1907-1913.

46. Nishina, P.M., Verstuyft, J., and Paigen, B. 1990. Synthetic low and high fat diets for the study of atherosclerosis in the mouse. J. Lipid Res. 31:859-869.

47. Loike, J.D., et al. 2004. Statin inhibition of FC receptor-mediated phagocytosis by macrophages is modulated by cell activation and cholesterol. Arterioscler. Thromb. Vasc. Biol. 24:2051-2056.

48. Tamura, Y., et al. 2004. Scavenger receptor expressed by endothelial cells I (SREC-I) mediates the uptake of acetylated low density lipoproteins by macrophages stimulated with lipopolysaccharide. J. Biol. Chem. 279:30938-30944. 